\title{
Analysis on the Strategy of Improving Customer Service of Hypermarkets
}

\author{
Xinxin Wang ${ }^{1, *}$ \\ ${ }^{1}$ School of Business Administration, Shandong Institute of Commerce and Technology, Jinan Shandong 250103, China \\ *Corresponding author. Email: wxxlbz@163.com
}

\begin{abstract}
The purpose of the work is to improve the competitiveness of hypermarkets and help them provide better service to customers. This paper's research objective is hypermarkets. It used practical investigation and theoretical research. It analyses the problems of hypermarkets' customer service: location, after-sale service, layout, price, settlement speed and online service. Finally, according to the problems of hypermarkets, some concrete measures are accordingly given. It is hoped that in the fierce market competition, hypermarkets can always stand in the perspective of meeting the needs of target customers, strengthen management, improve the effect of customer service, and enhance their competitiveness.
\end{abstract}

Keywords: hypermarket; service; display; price; efficiency

\section{INTRODUCTION}

in detail the improvement strategy of customer service of hypermarkets.

\subsection{Literature review of hypermarkets' service quality}

Zhigang Cha (2009) discussed how to improve the service quality of hypermarkets from six aspects: service concept, commodity quality, price, customer communication, human service and shopping environment [1]. Jianming Zhang (2011) discussed the strategies to improve the service quality of hypermarkets from ten aspects: service concept, convenience, commodity structure and quality, price image, promotion, Membership Service and shopping environment [2]. Chao Xia (2015) analyzed the strategies to improve service quality of hypermarket from the aspects of product, price and display [3]. Qian Yang (2016) analyzed the measures to improve customer satisfaction of hypermarkets from five aspects. They are: creating a good image, ensuring high-quality staff service, creating a comfortable shopping environment and providing convenient service [4]. Xiaopeng Yang (2020) mainly studied the customer service strategy of hypermarket from convenience [5].

Previous studies of hypermarkets' service improvement strategy mainly focused on the service in store, and stood in the perspective of hypermarket. On the basis of previous studies, combined with the current social-economic environment and technical environment, this paper compares the service of hypermarkets with the community group-buying service, finds out the shortcomings of hypermarkets, and focuses on the convenience and how to improve the efficiency of service, from six aspects: delivery, after-sales service, display, supply chain, settlement speed and online service. This paper discusses

\subsection{Classification of Chinese Retail Format}

According to the "Classification of Retail Formats" issued by the Ministry of Commerce in 2010, the retail industry was divided into 16 types, including hypermarkets. According to the definition of hypermarkets, hypermarkets should have five conditions: (1) site selection: the site selection of hypermarkets has higher convenience and population flow requirements, such as traffic arteries and residential areas. The service of hypermarkets should meet the needs of different consumers within the radiation radius; (2) business area: the business area of hypermarkets is more than 6000 square meters; (3) commodity structure: the commodity structure of hypermarkets needs to meet the daily needs of target consumers, such as clothing, food, housing, transportation and so on; (4) display: the entrances and exits are set separately, self-service, and centralized settlement; (5) parking conditions: because the radiation radius of hypermarkets is large, hypermarkets should have better parking conditions. Therefore, hypermarkets have such characteristics: the location requirements are high, and it must be in the residential areas or prosperous areas with high population flow; the commodity combination is wide and deep, and it needs to meet various needs of customers in the target market; the pricing should be differentiated, and it needs to take into account different customer groups and take cheap price strategies; by providing high quality and low cost goods, it can provide a one-stop shop and convenient services for customers, then it can make a profit. 


\subsection{A brief introduction of hypermarkets}

From the above analysis, we can summarize hypermarkets in this way. Hypermarkets refer to the commodity structure of food and daily necessities, self-service, Centralized Settlement Form. Since hypermarket began to appear in China in 1990s, it has been 30 years since the development of hypermarkets. Hypermarkets have also been divided into different forms according to the different scale of the business area. Such as: supermarkets (less than 6000 square meters of business area) and hypermarkets (more than 6000 square meters of the business area).

With the development of China's retail industry, there are more and more types of retail formats. Various formats with shops and those without shops are emerging and developing rapidly. China's retail market is in full bloom. In a word, hypermarkets have entered into the maturity period, and their market position has gradually changed from the absolute dominant position in the 1990s to the situation of fierce competition. If hypermarkets do not change quickly to adapt to market changes, they will be replaced by new formats or competitors.

\section{THEORIES OF SERVICE QUALITY}

\subsection{Service quality and its characteristics}

Service quality refers to the degree to which the service or service industry, based on its own facilities, provides services for customers to meet their material and spiritual needs. Service product is a process, the production and consumption of service are carried out at the same time, and customers participate in it, so the quality of service is very different from that of tangible products.

The characteristics of service quality are as follows. (1) Service quality is subjective. Service quality is a subjective category with strong subjectivity. From the perspective of service providers, service quality is the degree of conformity of service attributes to organization regulations; from the perspective of customer, service quality is the degree of service reaching or exceeding expectations. (2) Because the production and consumption of service happened at the same time, the process of service production and quality formation can be fully participated and perceived by customers, and customers can quickly judge the quality of the service process. (3) Service is holistic. The quality of service consists of many details. Any small fault may endanger the whole. The formation of good service quality requires active participation in all staff and the systematic and comprehensive monitoring of service institutions.

\subsection{Types of strategies to improve service quality}

The strategies of service enterprises to improve service quality include many aspects. (1) Service enterprises improve the service quality of personnel by training employees in service concepts and the way of behavior. (2) Service enterprises optimize the commodity display, strengthen the investment and construction of service hardware facilities and improve the service environment. (3) Service enterprises improve the information feedback system. In order to improve customer loyalty, we should obtain the feedback information of customer satisfaction through survey and visit, and take reasonable measures in time to improve customer loyalty. (4)Enterprises make reasonable pricing. Higher commodity prices often make customers have higher expectations of service quality, so enterprises should make reasonable pricing according to the service quality, so that customers will think that the good is good and inexpensive, so as to improve the loyalty to the enterprise. (5) Service innovation. Service innovation is mainly to improve the service process and reduce operating costs. Service innovation includes technological innovation, but it is a more soft technological innovation or non-technical innovation in organization, management, process and so on.

\section{THE SHORTCOMINGS OF CUSTOMER SERVICE OF HYPERMARKETS}

Compared with many other retail formats, hypermarkets have many shortcomings in customer service.

\subsection{Many stores are far away from customers}

Although most of the locations of hypermarkets are close to residential areas, because the business area of the stores is more than 6000 square meters, the customers in the residential area are only a part of the target customers of the hypermarket; their consumption amount is far from the goal of the hypermarket. The expected radius of the business circle is generally large, but as a result, only the customers from nearby residential areas occasionally patronize, and the customer flow of the store is small. Due to the high time cost of arriving at the store, the customers that are farther away often choose the closer convenience store, community small market, community group buying, or online shopping. In short, customers that are far away are unwilling and unnecessary to go to the stores of hypermarkets.

\subsection{After-sales service is low efficiency}

If customers want to return or exchange the goods after purchasing the goods in hypermarkets, they need to send the goods back to the store in person in most cases and find 
the after-sales service department of the hypermarket to deal with them. The whole return and exchange process are completed, which requires the customer to pay a certain amount of time, energy, physical strength and other costs. Compared with many online retailers, the return and exchange of goods is very convenient: even if there is no quality problem, the goods can be returned for seven days without reason, the return and exchange of goods can be made by appointment express delivery, and the cost of mailing also has freight insurance, which saves time and effort.

\subsection{Unreasonable display}

Many hypermarkets' display is very circuitous, so that customers can stay longer in the store. In the rise of hypermarkets, this kind of display was very popular with customers. At that time, shopping was one of the important ways of leisure and entertainment for customers. But now the demand of customers has changed, especially young customers are more in pursuit of shopping fast, so the convenience store format of three minutes to complete shopping, online shopping at home is very popular with many customers. Nowadays, many hypermarkets' display is very circuitous, "winding path leading to seclusion", and their customers' moving line is designed very long. Some of them are forced moving line design. If customers don't go shopping, it will take more than 15 minutes to finish a quick walk in the store. This is not in line with customers' demand for convenience.

\subsection{The price is higher}

The main commodities of hypermarkets are food and daily necessities. These goods are low technology content, large purchase volume, high purchase frequency, and they are just needed goods of consumers. The price sensitivity of these goods is very high, and the pursuit of low price is the choice of many customers. In recent years, the site rent, labor costs, equipment costs and other costs continue to rise, and the advantage of good quality and low price in the early development of hypermarkets is getting weaker and weaker. Compared with some community fresh specialty stores, the prices of many commodities in hypermarkets, especially fresh commodities, are not dominant. In the past, fresh food was popular in hypermarkets. Now, because of the high price, it is difficult for fresh food to bring high popularity to hypermarkets.

\subsection{Slow settlement}

Although the customer flow of hypermarkets is not high, there is always a queue at the cashier. Because there are fewer cashiers in stores, which is related to the generally higher labor costs, hypermarkets are reluctant to hire more cashiers. In recent years, many hypermarkets also began to be equipped with self-service cash registers, but the number is generally not much. Therefore, in the process of settlement and cashier, the efficiency of hypermarkets is low and the waiting time of customers is long.

\subsection{Imperfect online service}

According to the data released by China Internet Network Information Center June 2020, the number of internet users in China is 940 million, of which mobile internet users account for $99.2 \%$, the internet penetration rate reaches $67 \%$, and the number of mobile internet users is increasing. Now many people stay at home, online shopping has become a consumption habit. Adapting to the changing environment, many hypermarkets have established their own websites, official account numbers, or APP, or with some online shopping such as Taobao and JD, and established online shopping centers to open up online shopping channels for consumers. However, the category richness, quantity and details of online shopping of hypermarkets are far from meeting the needs of consumers, and the content of online shopping needs to be further improved.

\section{STRATEGIES FOR IMPROVING HYPERMARKETS' SERVICE QUALITY}

\subsection{To offer customers a free home delivery service}

For customers that are farther away, most hypermarkets can provide a free home delivery service. However, the survey found that although some hypermarkets have cooperative home delivery service with some platforms, such as JD, many of them not only charge basic freight, but also charge for packing goods. Although the freight plus packing fee of about five yuan is not much, it can be delivered home in many other businesses in the new market environment, the additional distribution and packing fee will restrain the consumption of a large number of customers. Hypermarkets can learn from RT mart, which is very popular with customers. RT Mart not only has the traditional free shopping shuttle service, but also has one hour delivery service. If the order is over 39 yuan and the weight is less than $10 \mathrm{~kg}$, the delivery fee is free. In addition, Hema Xiansheng has achieved the high efficiency of 30 minute door-to-door deliveries of $3 \mathrm{~km}$. Therefore, it is suggested that hypermarkets should reduce and reduce the distribution cost to customers to improve the distribution efficiency. 


\subsection{To increase the efficiency of after-sales service}

Hypermarkets should strictly control the quality of goods, and try to reduce the after-sales customer complaints caused by the quality of goods. After-sales service can learn from the practices of some e-commerce enterprises, such as seven day return without reason, quick refund, door-to-door pick-up service, etc. so as to improve the efficiency of after-sales processing and customer satisfaction.

First, hypermarkets should strictly control the quality of goods. Hypermarkets should adopt strict commodity quality management procedures in all aspects of pre-sale, sale and after-sale. For example, ALDI(Germany) has a strict quality assurance system when selecting goods: the products must be approved by law and regulations and tested by a third-party testing agency, and then the manufacturer can mass produce. There is a period of "trial sale" before the new products selected by ALDI go on sale[6].

Second, hypermarkets should provide online refund service. For after-sales services that only need to refund customers without return, hypermarkets can provide online refund service. For example, when a customer purchases a vegetable and finds it rotten after picking it up or receiving it, he or she does not need to go to the store. He or she just needs to take a photo and apply for a refund online. For online payment orders, many hypermarkets can provide this service, but the refund efficiency needs to be improved. But it is more difficult to provide after-sales services for customers that buy in the store. Therefore, hypermarkets can take certain measures to encourage customers to settle accounts with members as much as possible, or adopt online payment methods, so as to facilitate businesses to keep customers' consumption records and facilitate customers to apply for after-sales services. On the other hand, hypermarkets can provide fast refund service for high-quality customers to improve the maintenance rate of loyal customers.

Third, hypermarkets can learn from the practices of much online e-commerce for the return and exchange of customers, and provide freed door-to-door pick-up services, so as to reduce the time cost of customers and solve their worries about shopping. Hypermarkets can cooperate with express companies to provide door-to-door pick-up service for good return and exchange, no matter whether customers buy in stores or place orders online.

\subsection{To design a reasonable display}

First, the store display can be changed to free flow. Hypermarkets need to break the traditional grid display of stores and change it into a free flow display; shorten the original forced long customer moving line; with the trend of improving customer consumption level, stores can be designed and arranged into multiple display themes. In this way, customers can quickly find the goods they need when they go to the store, and they can also complete the shopping in a short time. Hypermarkets can learn from Lecheng hypermarket in Hefei, Anhui Province. Since its first store opened, Lecheng hypermarket has been very popular. One of the most important reasons is that in addition to its accurate selection of products, the unique display of stores. Lecheng hypermarket is known as "China's first future hypermarket" and "China's most beautiful hypermarket". Its storefront adopts the decoration style of animation (Moore Manor) elements. The overall layout of the hypermarket is " $\mathrm{U}$ " shaped, which is divided into food and non-food areas. The shelves are curved. Different types of goods' shelf style and colour are different greatly increased the sense of consumer experience.

Second, hypermarkets should improve environmental comfort and safety. Affected by the novel coronavirus pneumonia, customers will worry about their safety when they patronize closed retail outlets. In the special period, stores should do the most basic environmental disinfection, ventilation, detailed investigation into customers and so on. In addition, with the improvement of people's living standards, hypermarket stores should further improve the comfort of store environment, such as improving the comfort of store decoration, improving the applicability of equipment and so on.

Third, hypermarkets should make a strategic transformation in time. Wal-Mart's latest store opening plan of China shows that its overall business planning is "small", increasing the proportion of compact hypermarkets and community stores. The overall development trend of improving the store size of daily necessities retail enterprises is "small and beautiful" and "small and refined". The smaller the store size, the more flexible the location; the smaller the business circle, the closer to the target customers, the more convenient the service. Therefore, the new development of hypermarket stores, the development trend should be to the community type small-scale store transformation.

\subsection{To optimize the supply chain}

For commodities with high price sensitivity, such as fresh products, hypermarkets need to strengthen management, optimize supply chain, reduce purchasing cost and sales price to attract and maintain customers. In the past, in the period of rapid development of hypermarkets, compared with suppliers, hypermarkets were in the absolute dominant position in the channel, and with the help of their dominant position, hypermarkets charged a large number of channel fees to suppliers, so they could get high profits. But now the market competition is fierce, and the channel advantage of hypermarkets no longer exists. Now we need to take action from the perspective of the whole supply chain to improve efficiency, reduce the intermediate links between procurement and reduce costs. The fresh food management of hypermarket can learn from Yonghui: Yonghui's fresh food adopts the direct purchasing mode, a large number of fresh food purchasing personnel actively go out to find 
high-quality goods, and the fresh food management pays great attention to and strengthens the detail management, so Yonghui's fresh food profit is very high, but the loss is very low.

\subsection{To improve the efficiency of settlement}

For the problem of long waiting time of customers at the cashier, hypermarkets can improve the efficiency of manual cash registers and increase the number of selfservice cash registers.

First, hypermarkets should improve the efficiency of manual cash register. The cashier department should arrange shifts reasonably, not only to ensure that there are enough cashier services in the peak period of passenger flow, but also not many cashiers waiting for customers in the low period of passenger flowed. It is also necessary to strengthen the training of cashiers, because the cashiers in many hypermarkets are highly mobile, and many cashiers are not proficient in technical operation, thus affecting the efficiency of cashing Cashier pre-job training and other measures to improve the efficiency of customer service cashier.

Second, hypermarkets should increase the number of selfservice cash registers. Compared with manual cash registers, the cost of self-service cash registers is lower and more convenient. Although there are self-service cash registers in many hypermarket stores, the number is generally small, which can't solve the problem of customers queuing in peak passenger flow. According to the composition of target customers, hypermarkets can be equipped with more self-service cashier equipment. Of course, in order to facilitate some customers that can't operate the self-service cash register and those who are not willing to self-service, a certain number of manual settlement exits should also be reserved.

\subsection{To improve the online service quality}

First, hypermarkets should increase the depth of categories and the number of individual products. The number of online sales platforms of hypermarkets is generally relatively rich. Most of the daily consumption categories are available. However, in terms of the depth of each category, the number of individual products is relatively small. Many brands and individual products sold by stores are not available on the online platform. Because of the long-distance, customers are unwilling to buy in stores, and many customers' needs can't be met, so they have to look for other channels to buy. Therefore, the number of items on the online platform of hypermarkets needs to be increased.

Second, hypermarkets should enrich the commodity service. Most of the details of the items on the online platform of hypermarkets are too simple; sometimes even the most basic information is difficult for customers to find. Therefore, the single product information about hypermarkets should ensure the most basic commodity name, price, origin, grade, specification, model, date and so on. You can also introduce the characteristics of the goods, use methods, preservation methods, so that customers can understand the disposal and use of the goods. In addition to the most basic text with pictures, the form of commodity information introduction can also increase the video introduction form commonly used by online businesses, so the effect can be more vivid.

\section{CONCLUSION}

In a word, hypermarkets should be fully aware of the shortcomings of their services, keep up with the pace of social development, and meet the changing needs of customers. Hypermarkets should meet customer needs through a variety of strategies. Hypermarkets should improve the quality of goods and reduce costs, through the combination of online and offline to improve the service related to commodity sales, optimize the display of stores, strengthen internal management, etc. Only in this way, hypermarkets can improve the effect of customer service and continue to win the trust and support of customers in the fierce market competition.

\section{REFERENCES}

[1] Zhigang Zha, Strategies for improving customer satisfaction of large chain hypermarkets [J], Jiangsu Commercial Forum, 2009 (08):11-13(In Chinese)

[2] Jianming Zhang, Strategies for improving customer satisfaction of hypermarkets [J], Shanghai Business, 2011 (08):15-17(In Chinese)

[3] Chao Xia, Ping Wang, Xue Dong, strategies for improving customer satisfaction of large chain hypermarkets [J], Chinese Foreign Entrepreneurs, 2015 (09):24-25(In Chinese)

[4] Qian Yang, Yuhan Zhou, The research on improving customer satisfaction of large chain hypermarkets [J], Market weekly, 2016 (09): 52-53(In Chinese)

[5] Xiaopeng Yang, The research on the convenience influence of service on customer satisfaction [J], Market weekly, 2020 (11): 72-74(In Chinese)

[6]Chaoping Wang, The strategy analysis of German ALDI in China [J], Modern Business, 2020 (1): 9-10(In Chinese) 